\title{
Estimating the Translog Cost Function for the Telecommunications Sector in Saudi Arabia: The Case of Saudi Telecom Company: An Empirical Study
}

\author{
Salim Bagadeem ${ }^{1}$ \\ ${ }^{1}$ Vice Rector of Academic Affair, Arab Open University, KSA \\ Correspondence: Dr Salim Bagadeem, Vice Rector of Academic Affair, Arab Open University, KSA. E-mail: \\ Bagadeem@arabou.edu.sa
}

Received: October 27, 2020

Accepted: December 10, 2020

Online Published: January 11, 2021

doi:10.5430/ijfr.v12n3p19

URL: https://doi.org/10.5430/ijfr.v12n3p19

\begin{abstract}
The objective of this research paper is to estimate a translog cost function for the Saudi Arabian telecommunications sector. Telecommunications sector is one of the rapidly growing sectors during the past decade nationwide. A Saudi Telecom Company (STC) data set has been used, as STC has the largest share of the telecommunications sector in Saudi Arabia. Three input cost factors have been considered: marketing and sales, capital and other expenditures. The outputs were total revenue and number of subscribers. The estimation results show that marketing and sales costs are the most important productive components and that capital costs come next. The demand price elasticity values suggest that capital is the most important factor in terms of price sensitivity, which underlines the importance of capital and technology supplies as a necessary component, primarily for the telecommunications sector. From the findings, the telecom sector today relies on advanced technology that incurs high cost. Searching for appropriate funding mechanisms is logical and even necessary for sophisticated technologies and increasing costs. Upgrading marketing techniques, supporting customer services programmes and developing training programmes would yield excellent outcomes and enhance performance. The estimation results end with checking the existence economics of scale, and it has been found that the industry has increasing returns to scale. Therefore, it would be highly recommended to expand the services offered by the telecommunications sector.
\end{abstract}

Keywords: translog cost function, Saudi telecom company, telecommunications sector, scale economies, cost efficiency

\section{Introduction}

In Saudi Arabia, growth of investments and the expansion of telecommunications services has led to a noticeable increase in the contribution of telecom activities to the GDP. According to the Communication and Information Technology Commission Annual Reports (2005-2017), the telecom sector achieved approximately 71.6 billion Saudi riyals in total direct revenues from operations in Saudi Arabia by the end of 2016. The volume of spending on telecommunications services in the Kingdom was approximately 130 billion riyals in 2016. This has attracted investments to this sector and resulted in a rise in its contribution to the GDP, reaching six per cent by the end of 2016. The Saudi Telecom Company (STC) is the leading telecommunications services' provider in Saudi Arabia' with a strong international presence that enables STC to deliver a variety of services to customers. STC is considered to be the national telecommunications company of Saudi Arabia, and it has the largest capital and investments of the telecommunications industry in the Middle East, with a total of 54 million subscribers. The Saudi Arabian telecommunications sector has three major players: STC, Mobily and Zain. STC dominates the sector, with approximately 50\% of the market share, based on the report Saudi Telecom Company (STC) Reinstating Coverage, Riyad Capital, released on 16 December 2015.

STC was founded on April 1998 as a Saudi company pursuant to a royal decree. The decree authorized the transfer of the telegraph and telephone division of the Ministry of Post Telegraph to a publicly traded company. Initially, the company was wholly owned by the government of the Kingdom of Saudi Arabia (KSA). On 22nd September 2002, the government, pursuant to a Council of Ministers' resolution dated 9th September 2002, sold 30\% of its shares to the public and commenced its operations as the unique provider of telecommunications' services at KSA. The 
company has made various investments in affiliates, subsidiaries and joint ventures, collectively known as the 'Group' (STC Consolidated Financial Statements, different years). Accordingly, this study will consider data extracted from the STC financial reports to depict the Saudi telecom sector.

This paper will be organised as follows: After the introduction in section 1, section 2 presents the literature review, including applied analysis of TMCF and related work. Section 3 describes both the methodology of the econometric model and the model hypotheses. The statistical analysis and the estimation results are reported in Section 4. The summary and conclusion are in section 5.

\subsection{Problem Statement}

From the early stages, communication technologies have made great advances, providing the capability to carry large volumes of voice, data, and videos. The telecommunications sector has recently been developed and extended through substantial investments from both the private and the public sectors. In addition, it has positively boosted the efficiency of other productive sectors of the economy. Moreover, new technology implementation such as digital switching, fibre optics, satellites, mobile communications and the Internet have brought dramatic increases in the cost of providing these services. The new telecommunications technologies are intensively integrated with technology from broadcasting, computer, and new electronics' industries, providing a unified infrastructure for information transmission and processing. Such improvement in technologies should increase the efficiency of the production factors in telecommunications industry, and that, in turn, should be reflected in reducing costs. If cost-cutting is required, then it can be biased towards a production factor. For instance, technological changes lead to a decline in the cost of labour per unit of production. When such bias is apparent, the relationship between the costs of labour and capital per unit of production is changed. In the long term, technological change could impact the level of employment growth and capital accumulation. Several studies aimed to investigate the cost and production efficiency in the telecommunications sectors. These studies are mentioned later in at the same section.

However, the Saudi telecommunications industry operated for decades in a monopoly-based environment that no longer exists. It is a competitive market now. Hence, seeking efficiency is the aim of any service provider. This calls for providing the best quality service for less cost which, in turn, would require revising the cost structures. And, definitely, to avoid the negative impact of expenditure rationalization policy and maintain a high level of performance, the cost of services must be linked to their efficiency, which is achieved by studying and analysing cost elements. This paper investigates the cost efficiency of the Saudi telecommunications sector and it examine the existence of scale of economics. And, it is the first of its kind in using the translog cost function in measuring the effectiveness of privatisation on the telecommunications sector after decades of monopoly.

\subsection{Objectives}

The telecommunications services can be examined empirically using either production or cost functions. The cost function of any telecommunications project identifies its minimum cost of providing services, given the prices of input factors. This paper estimates the translog multiproduct cost function (TMCF) for the telecommunications sector using STC quarterly time series data for the period 2003-2017. This cost function uses the input cost factors to determine the different levels of cost and input production prices that compose the cost function during the study period. The input cost factors that will be used for this study are as follows:

1) Price of sales and marketing

2) Price of capital

3) Price of other services

Output is classified into two types; total revenue and numbers of subscribers. However, relatively few studies have been concerned with assessing the efficiency levels of the telecommunications industry. New technology has been found a main factor to enhance efficiency. Efficiency level can be attributed to a particular production factor that we try to investigate. However, the basic aim of this study is to address the cost structure of the Saudi telecom sector by using an appropriate econometric model. The intention is to analyse and measure cost factors and estimate the price elasticities of inputs, substitution and cross-substitution. This, in turn, enables analysis of the significance of substitution among input factors. In addition, the study aims to examine the existence of economies of scale among different levels of output in telecommunications sector, since the existence of such economies has been one of the basic arguments justifying the efficiency of the sector.

\section{Literature Review}

Theoretically, the translog cost function is used widely in econometrics research that describes production techniques. 
In the early stages, econometric models such as the linear model were simple and easy to measure; they then developed with the duality between production and costs and the appearance of nonlinear models. Then it became possible to initiate a functional form without putting pre-constraints on the form of production. The general functional model became more flexible in analysing production forms and cost behaviour without these constraints. This section will shed light on contributions and developments in the field of cost function that was developed by Christensen, Jorgenson and Lau (1973).

\subsection{Historical Evolution of the Translog Cost Function}

The cost function of economic analysis of demand inputs and substitution elements is a good example of the strong relationship between economic theory on the one hand and econometrics on the other, using mathematical analysis. Also, the economic theory of production and cost calls for maximizing profits and minimizing costs to determine supply factors using necessary and sufficient condition constraints. The regular form of the cost function can be as follows:

$$
\mathrm{C}=\mathrm{f}(\mathrm{Y}, \mathrm{P} 1, \mathrm{P} 2, \ldots \ldots \ldots, \mathrm{Pn})
$$

Where:

$\mathrm{C}=$ total cost

$\mathrm{Y}=$ outputs

$\mathrm{P}=$ prices of inputs

One of the earlier theories was developed by Cobb and Douglas (1928) and was dubbed the Cobb-Douglas function. It was criticized because of the constant returns to scale. To overcome this limitation in the Cobb-Douglas function, Arrow, Chenery and Solow (1961) put restrictions on it to add some flexibility. They introduced a so-called Constant Elasticity of Substitution Function, thus retaining the hypothesis of homogeneity. Different studies have been conducted to address these limitations. Diewert (1971) presented the general linear function in the following form:

$$
y=\alpha_{\circ}+\sum_{i=1}^{n} \alpha_{i} \sqrt{x_{i}}+\sum_{i=1}^{n} \sum_{j=1}^{n} \alpha_{i j} \sqrt{\left(x_{i} x_{j}\right)}
$$

In 1973, Christensen et al. presented the transcendental logarithmic function as follows:

$$
\ln \mathrm{y}=\alpha+\sum_{\mathrm{i}=1}^{\mathrm{n}} \alpha_{\mathrm{i}} \ln \mathrm{x}_{\mathrm{i}}+\frac{1}{2} \sum_{\mathrm{i}=1}^{\mathrm{n}} \sum_{\mathrm{j}=1}^{\mathrm{n}} \alpha_{\mathrm{ij}}\left(\ln \mathrm{x}_{\mathrm{i}}\right)\left(\ln \mathrm{x}_{\mathrm{j}}\right)
$$

The quadratic function then presented by Lau (1974) is as follows:

$$
\mathrm{y}=\alpha_{\circ}+\sum_{\mathrm{i}=1}^{\mathrm{n}} \alpha_{\mathrm{i}} \mathrm{X}_{\mathrm{i}}+\sum_{\mathrm{i}=1}^{\mathrm{n}} \sum_{\mathrm{j}=1}^{\mathrm{n}} \alpha_{\mathrm{ij}} \mathrm{x}_{\mathrm{i}} \mathrm{x}_{\mathrm{j}}
$$

All previous functions can be used as production, profit or cost functions, although the cost function is widely used as a function to analyse productivity growth. The practical advantage of this function lies in the ease of calculating the relationship of the minimising costs of the demand function to the production factors. Also, the partial differentiation of the cost function for the prices of the production factors gives demand functions to the production factors, and the total value of inputs is equal to the cost. In the end, the usefulness of cost function analysis is in the duplication of production and costs. However, Binswangr (1974) proposed that the use of cost function rather than the production function for estimating production parameters is better for explaining the variables of the production function from the production function itself for the following reasons:

1. It is not necessary to assume first-order homogeneity in the flow of production to reach the estimated equation. Cost function is homogeneous in prices regardless of the homogeneity in production function proprieties.

2. To obtain the elasticity of demand or substitution in the case of multiple elements of production, it is necessary to invert the matrix of the production function coefficient. In the case of a translog cost function, this procedure is not required. 
3. Most methods used when estimating the production function cannot address either the problem of varying efficiency between parameters or differences in economies of scale, whereas the logarithmic function does so easily.

4. This cost function does not encounter the problem of multicollinearity between input factors, which is usually encountered by the production function and the costs at the estimate.

\subsection{Related Works}

Different applied studies have been aimed at measuring and analysing the translog cost function, either at the level of telecommunications sector or at other service levels. The first econometric studies of the production processes of North America telecommunications industries were published in the early 70 s before the existence of the translog cost function using Cobb-Douglas production functions. At a later stage, a number of econometric studies employed increasingly advanced production functions. Vinod $(1975,1976)$ developed a model with two outputs and two inputs for the translog production function for the American Telephone \& Telegraph Company (AT\&T). To improve the goodness of estimation, Vindo used ridge regression. The document that was presented by AT\&T to the Federal Communications Commission contains several differently specified production functions and detailed explanations that attempt to measure technological changes. Corbo (1976) applied a single-output two-factor input translog production function with a Hicks-neutral technological change for Bell Canada. At a later stage, Corbo et al. (1978) extended the estimation to multiple output production function using a two-output three-factor model, where the production possibility frontier was translog on output and Cobb-Douglas on inputs. The estimated equations were derived from the first-order conditions for cost minimization, under a regulatory constraint for the rate of return.

Increasing investigation of the theory of duality during the 1970s led to the realization that it was not only possible but also necessary to represent the production structure of telecommunications organisations through the dual cost function. Cost functions were attractive in the case of multi-product firms, since the number of the exogenous output variables could be increased easily. Demand for input factors by the cost-minimising firms for factors of production can be derived by partially differentiating the cost function with respect to the factor prices of inputs. According to Smith and Corbo (1979) cost functions generate sets of estimates for the economic properties of the production technology, including direct measures for pieces of input as marginal cost and the cost elasticity with respect to output, technological changes, and factor prices. Ferenc and Bernard (1987) conducted a survey describing and analysing a large body of empirical evidence on the aggregate economic properties of the production structures of American and Canadian telecommunications sectors. The survey examined several aggregate econometric cost models of AT\&T and Bell Canada, which were estimated earlier by several researchers. The researchers concluded that these forms show a high degree of consistency when using the translog function in the telecommunications sector.

Foreman (1999) estimated the economies of scale of the cellular market in the USA and found that scale economies exist throughout the cellular market system. The input variables used were total cost, including total capital network costs, sales and marketing costs, operations support costs, general administration costs and the net interest. Two output measures were used: the number of subscribers and another controlled measure. A translog cost function for the Indian telecommunications company DoT was estimated by Das (2000). The estimates showed the existence of high economies of scale and economies of scope in the technology used by DoT. In a study for the transportation sector, Sanches (2000) estimated the levels of productivity, efficiency and technical change for several European railway companies. Unlike other studies, and based on production functions, the estimation included a stochastic frontier cost function. The results showed that technical progress is the main source of productivity. Bloch et al (2000) examined labour and capital saving technical change for the Australian telecommunications sector. The model estimated the Telestra System data from 1926 to 1991. Quadratic log-structures for input prices and output were used to estimate the economies of scale, economies of scope and subadditivity. Model estimation showed that the production of Australian telephone services exhibits economies of scope and no economies of scale. Soro (2000) estimated the cost structure and regulation of the telecommunications industry in the USA. The semi-parametric model used the translog cost function, where output was entered non-parametrically. The outputs showed the presence of scale economies in the local exchange carrier. Scale economies seemed larger for small firms than for large firms. The result explained the wave of merging and consolidation that was going on in the US telecommunications industry in that era. However, the present study is considered the first of its kind in measuring the cost structure and production efficiency for the Saudi telecommunications sector. Mancuso (2012) provided insights into the consequences of the Italian communications regulatory authority's decision to impose of separation on the incumbent telecommunications operator. The research finding supports that type of separation. Also, the study 
offered an empirical evidence on the advantages of translog function in analysing the multiproduct cost structure of a telecommunications sector. Similar to Hendrawan and Nugroho (2019), this study used the number of subscribers and total revenue as indicators of the output. The efficiency of 14 operators in Southeast Asia between 2008 to 2017 has been measured. The study finding showed that telecommunication companies that has the lowest efficiency level because of the value of its output (subscribers, revenue), did not show any positive correlation to its efficiency value. In another study of the economics of scale, Onghena (2014) analysed the cost structure by using a translog cost function for the period from 1990 to 2010 for FedEx and UPS. The finding supported strong scale and density economies in the short and the long term.

\section{Proposed Methodology and Cost Model}

This study follows a non-linear form developed by Christensen et al. (1973) to build TMCF in logarithmic form. This function has arguments regarding the level of output and input prices, and it is a second-order approximation to a cost. To define the initial TMCF, the cost function can be written in the following general logarithmic form:

$$
C=\mathrm{g}\left(\ln \mathrm{y}_{1}, \ln \mathrm{y}_{2}, \ldots \ldots . ., \ln \mathrm{y}_{m}, \ln \mathrm{p}_{1}, \ln \mathrm{p}_{2}, \ldots \ldots ., \ln \mathrm{p}_{N}\right)
$$

The general specification of the TMCF imposes no prior restriction on the production structure, that is, it does not impose ex ante neutrality, homotheticity, constant returns to scale or unique elasticities of substitution. The popular form of TMCF, with two outputs and three inputs, is written as follows:

$$
\begin{aligned}
\ln \mathrm{c}=\alpha_{\circ} & +\sum_{i=1}^{m}\left(\frac{\partial \ln \mathrm{c}}{\partial \ln \mathrm{y}_{i}}\right) \ln \mathrm{y}_{i}+\sum_{i=1}^{n}\left(\frac{\ln \mathrm{c}}{\ln \mathrm{p}_{i}}\right) \ln \mathrm{p}_{i} \\
& +\frac{1}{2} \sum_{i=1}^{m} \sum_{j=1}^{m}\left(\frac{\partial^{2} \ln \mathrm{c}}{\partial \ln \mathrm{y}_{i} \partial \ln \mathrm{y}_{j}}\right) \ln \mathrm{y}_{i} \ln \mathrm{y}_{j} \\
& +\frac{1}{2} \sum_{i=1}^{n} \sum_{j=1}^{n}\left(\frac{\partial^{2} \ln \mathrm{c}}{\partial \ln \mathrm{p}_{i} \ln \mathrm{p}_{j}}\right) \ln \mathrm{p}_{i} \ln \mathrm{p}_{j} \\
& +\sum_{i=1}^{m} \sum_{j=1}^{n}\left(\frac{\partial^{2} \ln \mathrm{c}}{\partial \ln \mathrm{y}_{i} \partial \ln \mathrm{p}_{j}}\right) \ln \mathrm{y}_{i} \ln \mathrm{p}_{j}
\end{aligned}
$$

Where (c) denotes total cost

$\left(\mathrm{y}_{\mathrm{i}} \ldots . . \mathrm{y}_{\mathrm{m}}\right)$ denote output

$\left(\mathrm{p}_{\mathrm{i}} \ldots \mathrm{p}_{\mathrm{n}}\right)$ denote input price factors

Assuming the stability of the self-derivative and cross one of the logarithmic function, estimating parameters in the regression equation can be found as follows:

$$
\begin{array}{r}
\alpha_{i}=\left(\frac{\partial \ln \mathrm{c}}{\partial \ln \mathrm{y}_{i}}\right) \\
\alpha_{i \mathrm{ij}}=\left(\frac{\partial^{2} \ln \mathrm{c}}{\partial \ln \mathrm{y}_{i} \partial \ln \mathrm{y}_{j}}\right) \\
\beta_{\mathrm{lij}}=\left(\frac{\partial^{2} \ln \mathrm{c}}{\partial \ln \mathrm{p}_{i} \ln \mathrm{p}_{j}}\right) \\
\gamma_{\mathrm{ij}}=\left(\frac{\partial^{2} \mathrm{nl} \mathrm{c}}{\partial \ln \mathrm{y}_{i} \partial \ln \mathrm{p}_{j}}\right)
\end{array}
$$

And then, TMCF can be rewritten as follows:

$$
\begin{aligned}
\ln \mathrm{c}= & \alpha+\sum_{i=1}^{m} \alpha_{i} \ln \mathrm{y}_{i}+\sum_{i=1}^{n} \beta_{i} \ln \mathrm{p}_{i} \\
& +(0,5) \sum_{i=1}^{m} \sum_{j=1}^{m} \alpha_{i j} \ln \mathrm{y}_{i} \ln \mathrm{y}_{j}
\end{aligned}
$$




$$
\begin{aligned}
& +(0,5) \sum_{i=1}^{n} \sum_{j=1}^{n} \beta_{i j} \ln \mathrm{p}_{j} \ln \mathrm{p}_{j} \\
& +\sum_{i=1}^{m} \sum_{j=1}^{n} \gamma_{i j} \ln \mathrm{y}_{i} \ln \mathrm{p}_{j}
\end{aligned}
$$

Where

$$
\left(\alpha_{i j}=\alpha_{j i}\right) \text { and }\left(\beta_{i j}=\beta_{j i}\right)
$$

Since the cost function should show that the homogeneity of degree is one in the prices of the production factors, the following restrictions are necessary and sufficient for the condition of linear homogeneity in the prices of production factors.

$$
\sum_{j=1}^{n} \beta_{j}=1, \sum_{i j}^{n} \beta_{\mathrm{ij}}=0(\mathrm{i}=1,2,3, \ldots \mathrm{n})(\mathrm{j}=1, \mathrm{k}, \mathrm{s})
$$

Homogeneity in production requires that the cost function be homogeneous in output. And that adds the following restrictions to the earlier one:

$$
\sum_{i=1}^{m} \alpha_{i j}=0, \sum_{i=1}^{m} \gamma_{\mathrm{ij}}=0
$$

When the cost function is the same as the previous characteristics, the factor demand function can be derived by taking the partial differential of the cost function for input prices using the Shephard lemma (1970) which is as follows:

$$
\frac{\partial \ln \mathrm{c}}{\partial \ln \mathrm{p}_{i}}=\frac{p_{j}}{c} \frac{\partial \mathrm{c}}{\partial \mathrm{p}_{j}}=\frac{p_{i} \mathrm{x}_{i}}{c}=\mathrm{s}_{i}
$$

Since $S_{i}$ is the share of production factors $i$ of the total costs, and from the TMCF, production factor shares can be derived as follows:

$$
S_{i}=\beta_{i}+\sum_{j} \beta_{i j} \ln \mathrm{p}_{j}+\sum_{j} \gamma_{\mathrm{ij}} \ln \mathrm{y}_{j}
$$

The estimated shares' elasticities can be obtained by deriving the logarithmic cost function twice for input prices as follows:

An estimate of the degree of cost response to change in the output level - cost elasticity for the output level - can be obtained by driving TMCF twice for the level of outputs as follows:

$$
s_{\mathrm{yy}}=\frac{\partial^{2} \ln \mathrm{c}}{\left(\partial \ln \mathrm{y}_{i}\right)\left(\partial \ln \mathrm{y}_{i}\right)}=\frac{\partial \mathrm{s}_{\mathrm{yi}}}{\partial \ln \mathrm{y}}=\alpha_{y y}
$$

Elasticities of substitution can be obtained from TMCF. Uzawa (1962) proved that the substitution elasticities used by Allen (1939) can be written as follows:

Demand price elasticities can be obtained directly through the relationship with the elasticities of substitution as follows:

$$
\begin{aligned}
\sigma_{i i} & =\frac{\beta_{\mathrm{ii}}+\mathrm{s}_{\mathrm{i}}^{2}-\mathrm{s}_{\mathrm{i}}}{s_{i}^{2}} \\
\sigma_{i j} & =\frac{\beta_{\mathrm{ij}}+\mathrm{s}_{\mathrm{i}} s_{j}}{s_{i} s_{j}} \\
& =\frac{\beta_{\mathrm{ij}}}{S_{i} s_{j}}+1
\end{aligned}
$$$$
\mathrm{i} \neq \mathrm{j}
$$ 


$$
\begin{gathered}
e_{i i}=s_{i} \sigma_{i i}=\frac{\beta_{i i}}{s_{i}}+s_{i}-1 \\
e_{i j}=s_{i j} \sigma_{i j}=\frac{\beta_{i i}}{s_{j}}+s_{i}(i \neq j)
\end{gathered}
$$

The economies of scale $(e s)$, which is the percentage of change in output resulting from the change in the inputs of production in equal proportions, can be expressed as the relationship between the total costs and the output on the expansion path of production. Also, it is the amount of change in the total costs resulting from the changes in the final production levels. Brown-Cave-Christensen (1979) noted that estimates of the cost elasticity of outputs can be obtained directly from TMCF by deriving the function for outputs to obtain cost elasticity and can be as follows;

$$
\begin{gathered}
s c e=\sum_{i} \frac{\partial \ln \mathrm{c}}{\partial \ln \mathrm{y}_{i}} \\
=\sum_{i} \alpha_{i}+\sum_{j} \alpha_{i j} \ln \mathrm{y}_{j}+\sum_{j} \gamma_{i j} \ln \mathrm{p}_{j}
\end{gathered}
$$

Economies of scale can be defined by the following relationship:

$$
\text { sce }=1-\sum^{m} \frac{\partial \ln c}{\partial \ln y_{i}}
$$

If $($ sce $)=1$, then constant returns to scale exist

If $($ sce $)<1$, then economies of scale exist

If $($ sce $)>1$, then diseconomies of scale exist

\subsection{Model Hypotheses}

The Translog Econometric Model is based on several hypotheses that help to estimate the cost function proposed by Christensen et al. (1973). It assumes that this cost function is continuous and that its partial derivatives can be calculated. These assumptions are limited to the following:

- The cost function is an increasing function in both output and input prices.

- The share of each output in the total cost function increases in the level of production of this product and decreases in the output level of other outputs.

- The share of inputs in total costs is increasing as their prices increase.

- Self-substitution elasticities of inputs are negative.

- Cross-substitution elasticities are positive.

- This cost function is first-order homogeneous in the prices of the production factors, that is, function signs are not free.

\section{Data and Statistical Analysis}

The statistical analysis used quarterly time series data for the period of 2003-2017 that were constructed from the (STC) financial statements and reports (2017). These data can be used as components of TMCF and will enable understanding of the different levels of cost for the study period. The standard model examines the relationship between the dependent variable total costs $(T C)$ and the input price factors of production as independent variables. These factors are represented by marketing and sales cost $(P m)$ that are related to the marketing, distribution and sale of services divided by the number of subscribers. Here, it is worth mentioning that this factor includes labour cost. Capital cost $(P k)$ is represented by the yearly depreciation rate. Finally, other services cost $(P o)$ represents all administration and other costs divided by the number of subscribers. Outputs were classified into two different categories: the number of subscribers $\left(Y_{1}\right)$ and total revenue $\left(Y_{2}\right)$. At another stage, this will enable investigating the existence of scale of economies (sce).

To estimate the parameters of the standard form of TMCF and the model coefficients, the method of full information maximum likelihood will be used. This method is used extensively in estimating TMCF. It uses all the available information that increases the degree of freedom, thus enabling estimation of several simultaneous equations. Furthermore, this method was used because the cost function has significant coefficients for estimating scale of economies. 


\subsection{Estimation Results}

Estimation results for the translog cost function are presented in this section. Table 1, shows estimation outputs. Starting from the overall model fit, the overall fit is excellent; $\mathrm{R}^{2}=0.94$ for TC, 0.92 for the parameter of marketing and 0.89 for the parameter of capital.

For the estimated parameters, the point estimates are remarkably stable with respect to specification. The input factors $\beta \mathrm{m}, \beta \mathrm{k}$, Bo are the average shares of each input factor - marketing and sales, capital and other services, respectively - at the point when the prices of these factors and levels of production are near the expansion line of the production. The estimation results suggest that none of the variables employed should be omitted. The outputs show that marketing and sales cost, $\mathrm{Bm}$, is the most important productive component, with a share of $52 \%$. It is obvious that the telecommunications sector concentrates intensively on marketing activities and promotions to enhance productivity. As mentioned earlier, this factor includes labour cost, which contributes a large share of the marketing budget. Capital cost, $ß \mathrm{k}$, comes second, with a share of $35 \%$. Other services cost, $\beta_{\mathrm{O}}$, such as costs incurred in disposal of property plants, some administrative expenses and equipment maintenance, comes third, with a share of $13 \%$.

Table 1. Parameters estimation

\begin{tabular}{|c|c|c|}
\hline Parameter & Estimation & T-test \\
\hline$\beta \mathrm{m}$ & 0.52 & 57.56 \\
\hline$\beta_{\mathrm{K}}$ & 0.35 & 30.10 \\
\hline$\beta o$ & 0.13 & 43.90 \\
\hline$\beta_{\mathrm{mm}}$ & 0.15 & 6.87 \\
\hline$\beta_{\mathrm{kk}}$ & 0.58 & 5.85 \\
\hline$\beta_{\mathrm{oo}}$ & 0.16 & 3.25 \\
\hline$\beta_{\mathrm{mk}}$ & -0.20 & -2.66 \\
\hline$\beta_{\mathrm{ko}}$ & -0.37 & -2.22 \\
\hline$\beta_{\mathrm{mo}}$ & -0.12 & -4.12 \\
\hline$\alpha_{\mathrm{y}_{1}}$ & 0.35 & 1.95 \\
\hline$\alpha_{y_{2}}$ & 0.75 & 3.30 \\
\hline$\alpha_{\mathrm{y}_{11}}$ & 3.10 & 1.73 \\
\hline$\alpha_{y_{22}}$ & 4.95 & 1.95 \\
\hline$\alpha_{y_{12}}$ & -2.85 & -1.78 \\
\hline $\mathrm{R}_{\mathrm{TC}}^{2}$ & 0.94 & - \\
\hline $\mathrm{R}^{2}{ }_{\mathrm{M}}$ & 0.92 & - \\
\hline $\mathrm{R}^{2}{ }_{\mathrm{K}}$ & 0.89 & - \\
\hline
\end{tabular}

Looking at the pattern of substitution between the input factors $\beta_{\mathrm{mm}}, \beta_{\mathrm{kk}}$ and $\beta_{\mathrm{oo}}$, positive self-substitution elasticities values indicate that the share of the production component increases by increasing its price and decreases by 
lowering its price. On the other hand, negative self-substitution elasticities values indicate that the share of the production component declines by increasing its price and increases by lowering its price. However, the participation rate of each of the three production components has the same sign, showing that the share of inputs in total costs increases as their prices increase.

The estimated cross-share elasticities for the production elements show the effect of the change in the prices of the components of production on the share of the other elements of production. Since $\beta_{\mathrm{mk}}, \beta_{\mathrm{ko}}, \beta_{\mathrm{mo}}$ are negative, any increase in the price of any input factor will lead to a lower share of other production components in total costs.

For the estimated cost flexibility for output $\alpha_{\mathrm{y}_{1}}, \alpha_{\mathrm{y}_{2}}$, where $\mathrm{y}_{1}$ is the number of subscribers and $\mathrm{y}_{2}$ is the total revenue, these values demonstrate the estimation of the degree of cost response to change in output level. It is obvious that the values of these indicators are positive and that the total revenue $\mathrm{y}_{2}$ is the most important output in determining the total costs of the telecommunications service. Also, these indicators can be used to measure the degree of homogeneity of the function for production, that is $\sum_{i=1}^{2} \alpha_{Y i}=1.10$, indicating that the production process in the telecommunications services is yielding increasing returns to scale, i.e., the increase of all the input factors by a certain percentage will lead to a greater increase in the outputs.

On the other hand, the indicators $\alpha_{\mathrm{y}_{11}}, \alpha_{\mathrm{y}_{22}}$ express the estimation of the cost response to the output level. The degree of output cost response with the level of production changes is increasing when the sign of $\alpha_{\mathrm{y}_{11}}, \alpha_{\mathrm{y}_{22}}$ is positive and is decreasing when the sign is negative. Here, these indicators show that the degree of response of output costs increases with the same production output. Checking the degree of responsiveness of cross-cost elasticity to change in outputs $\alpha_{y_{12}}$ shows a negative sign, where the response rate of the output total revenue decreases with the increases of the output total number of subscribers and increases with the decreasing number of subscribers.

Elasticities of substitution measure the degree of substitution between two production inputs. The results are shown as maximum, minimum and average values. Considering the average value, the self-substitution elasticity of capital is the highest $\left(\sigma_{\mathrm{KK}}=-2.23\right)$, followed by the elasticity of marketing and sales $\left(\sigma_{\mathrm{MM}}=-0.55\right)$ and then the elasticity of the other services $(\sigma 00=-0.31)$. This indicates that the telecommunications sector tends to use the two input factors; marketing and capital intensively. Elasticities' values of input factors M, K, $\mathrm{O}$ are shown in Table 2.

Table 2. Elasticities table

\begin{tabular}{cccc}
\hline Estimation & $\sigma_{\mathrm{MM}}$ & $\sigma_{\mathrm{KK}}$ & $\sigma_{\mathrm{OO}}$ \\
\hline Max & -0.76 & -3.61 & -0.52 \\
Average & -0.55 & -2.23 & -0.31 \\
Min & -0.35 & -0.84 & -0.10 \\
Estimation & $\sigma_{\mathrm{MK}}$ & $\sigma_{\mathrm{MO}}$ & $\sigma_{\mathrm{OK}}$ \\
Max & 0.30 & 0.15 & 0.16 \\
Average & 0.48 & 0.30 & 0.18 \\
Min & 0.66 & 0.46 & 0.20 \\
Estimation & $e_{M M}$ & $e_{k k}$ & $e_{o o}$ \\
Max & -0.29 & -0.22 & -0.48 \\
Average & -0.23 & -0.16 & -0.33 \\
Min & -0.16 & -0.097 & -0.19 \\
\hline
\end{tabular}


The values of cross-elasticity of substitution explain the current nature of substitution between these inputs, and they all have positive signs. The average cross-elasticity of substitution between marketing and capital $\left(\sigma_{\mathrm{MK}}=0.48\right)$ is the largest in terms of the possibility of substituting marketing services and capital. Therefore, it can be proposed that telecommunications services use marketing and sales more intensively than they do other inputs. This is also supported by the value of the marketing and sales coefficient $\beta \mathrm{m}=0.52$, Table 1 , as this is the highest value. On the other hand, it can be noted that the substitution between capital and other services has the lowest value of cross-elasticity of substitution $\left(\sigma_{\mathrm{OK}}=0.18\right)$, as the costly elements of capital and technology make capital substitution less advantageous.

The demand price elasticity values were found to identify the price elasticities of input factors to determine the importance of each factor in the production. The average price elasticity values for all input factors show that the price elasticity of all production factors has a negative sign. Capital was found to be the most important factor in terms of price sensitivity, $e_{k k}=-0.16$, followed by the marketing and sales component, $e_{M M}=-0.23$. This underlines the importance of capital and technology supplies as a necessary commodity, primarily for the telecommunications sector.

As for the scale of economies, the average value of the cost elasticity for the estimated outputs in the model $($ sce $)<1$ and $=(0.68)$. Using Equation (10) on the estimated output, the scale of economies indicates a positive value, where

$$
\begin{gathered}
\text { sce }=1-\sum \frac{\partial \ln \mathrm{c}}{\partial \ln \mathrm{y}}>0 \\
\text { sce }=1-0.68=0.32
\end{gathered}
$$

This indicates that the telecommunications sector has increasing returns to scale. STC operates within the decreasing part of the long-run average cost function and has the advantage of reducing the average unit cost of output as it expands its production process.

\section{Summary and Conclusions}

The objective of this study has been to estimate a translog cost function and to show its internal structure for the telecommunications sector in Saudi Arabia. An STC data set has been used because STC has the largest share of the Saudi telecommunications market. We have estimated parameters that represent the cost share of inputs and the elasticities of cost share of input with respect to inputs. In addition, we have checked for substitutability and for scale of economies. Main conclusions are as follows: The point estimates are remarkably stable with respect to specification. The estimated values for parameters suggest that none of the variables should be omitted. Furthermore, the estimation results show that marketing and sales costs are the most important productive components, indicating that the telecommunications sector concentrates intensively on marketing and sales activities to enhance productivity. The pattern of substitution among inputs has been checked, and it has been found that the share of inputs in total costs increases as their prices increase. As for the estimated cost flexibility for output, total revenue and number of subscribers, it has been found that total revenue is the most important factor in determining the total costs of the telecommunications service. The demand price elasticity values indicate that capital is the most important factor in terms of price sensitivity. This underlines the importance of capital and technology supplies as a necessary input, primarily for the telecommunications sector. New technology can increase the efficiency of the factors of production. Out of this finding that marketing and capital has the highest possibility of substitution, it is noticeable that the telecommunications sector today relies directly on high technology that incurs high cost. The search for appropriate funding mechanisms is logical and even necessary because telecommunications technology has become more sophisticated, and its subsequent costs are increasing.

Also, the results have shown the importance of the input of marketing and sales activities. Hence, tending towards adopting new marketing techniques and supporting the necessary training programs become crucial to enhance performance. The estimated results ended with checking of the existence of scale economies and it has been found that the telecommunications sector has increasing returns to scale. Therefore, it is recommended to expand the services offered by the telecommunications sector. Expansion of providing the service by STC or other service providers can be beneficial and profitable as the industry operating at the downward path of the average total cost curve. In other words, increasing returns can be extended over time by getting more output out of every additional input, and that resulting in a decreasing average total cost.

However, the study is limited to STC as a representative for the telecommunication sector in Saudi Arabia. Increasing the study sample to include the entire telecommunication companies in Saudi Arabia would enhance the 
generalizabilityof the finding. Although we attempted to examine all available variables for input and output, this was not always possible. Other important variables, such as the price of technology can be included as important input factor. This would add value to the study, especially when analysing the advance technology for the telecommunication sector.

\section{Acknowledgment}

The author gratefully acknowledges the Arab Open University, Saudi Arabia, supporting and funding this research.

\section{References.}

Allen, R. G. D. (1939). Mathematical Analysis for Economists. The Annals of the American Academy of Political and Social Science, 205(1), 154-155.

Arrow, K., Chenery, H., Minhas B., \& Solow, R. (1961). Capital-Labour Substitution and Economic Efficiency. Review of Economic and Statistics, 43(3), 225-250.

Bagadeem, S., \& Ahmad, M. (2020). Sovereign Debt and Defaults: A global study. NMIMS Management Review, $38(2), 110-122$.

Binswanger, H. (1974, May). Cost Function Approach to the Measurement Elasticities of Substitution. American Journal of Agriculture Economics, 56(2), 377-386.

Bloch, H., Madden, G., \& Scott, J. (2001). Economies of Scale and Scope in Australian Telecommunications. Review of Industrial Organization, 18, 219-227.

Brown, R. S., Caves, W., \& Christensen, L. R. (1979). Modeling the Structure of Cost and Production for Multiproduct Firms. Southern Economic Journal, 46(3), 256-273.

Christensen, L., Jorgenson, D., \& Lau, L. (1973). Transcendental Logarithmic Production Frontiers. Review of Economics and Statistics, 55(1), 28-45.

Coma, C. W., \& Douglas, P. H. (1928). A theory of production. In Proceedings of the Fortieth Annual Meeting of the American Economic Association, 139, 165-166.

Communication and Information Technology Commission. 2005-2017 annual reports. Retrieved from http://www.citc.gov.sa/en/mediacenter/annualreport/Pages/default.aspx

Corbo, V. (1976). Rate Adjustment Guidelines for Regulated Industries: A model for Bell Canada. Institute of Applied Economic Research. Montreal: Concordia University.

Corbo, V., Breslaw, J. A., Vrljicak, J. M., \& Vapessaran, A. R. M. (1978). A Simulation Model of Bell Canada: Final report. Special Study, 78-001, Institute of Applied Economic Research, Concordia University, Montreal.

Das, N. (2000). Information Economics and Policy 12 (2000) 133- 154 Economic Analysis Unit. Indian Statistical Institute, Bangalore 560059, India.

Diewert, W. (1971). An Application of the Shephard Duality Theorem: A Generalized Leontief Production Function. Journal of Political Economy, 79(3), 481-507.

Foreman, R., \& Beauvais, E. (1999). Scale Economies in Cellular Telephony: Size Matter. Journal of Regulatory Economics, 16, 297-306.

Hendrawan, R., \& Nugroho, K. (2018). Telecomunication Sector Reform In Southeast Asia: A New Rationality. Global Journal of Business and Social Science Review, 6(4), 147-154.

Kiss, F., \& Lefebvre, B. (1987). Econometric models of Telecommunications firms. Revue economies, 38(2), 307-374.

Lau, L. J. (1974). A Characterization of the Normalized Restricted Profit Function. Stanford: Institute for Mathematical Studies in the Social Sciences, Stanford University.

Mancuso, P. (2012). Regulation and Efficacy in Transition: The Case of Telecommunications in Italy. International Journal of Production Economics, 135(2), 762-770.

Onghena, E., Meersman, H., \& Voorde, E. (2014). A translog Cost Function of the Integrated Air Freight Business: The Case of FedEx and UPS. A transportation Research Part A: Policy and Practice, 62, 81-97.

Sanchez, P., \& Villarroya, J. (2000). Efficiency, Technical Change, and Productivity in the European Sector A Stochastic Frontier Approach. International Journal of Transport Economics, 27(1), 55-76. 
Saudi Telecom Company (STC) Reinstating Coverage, Riyad Capital, December 16, 2015.

Saudi Telecom Company. 2003-2017 Financial Statements. Retrieved from https://www.stc.com.sa/wps/wcm/connect/english/stc/investorRelations/financialStatement

Saudi Telecom Company. 2004-2017 Annual Reports. Retrieved from https://www.stc.com.sa/wps/wcm/connect/english/stc/investorRelations/annualReport

Shephard, R. (1970). Theory of cost and production function. New Jersey: Princeton University Press.

Soro, T. O. (2006). Cost structure and regulation in the telecommunications industry, Doctoral dissertation. University of Southern California.

Uzawa, H. (1962). Production functions with constant elasticities of substitution. The Review of Economic Studies, 29(4), 291-299.

Vinod, H. D. (1975, April). Applications of new ridge regression methods to a study of Bell System scale economies. Federal Communication Commission, Docket No. 20003, Bell Exhibit No. 42.

Vinod, H. D. (1976a, August) Bell System scale economies and estimation of joint production functions. Federal Communications Commission, Docket No. 20003, Bell Exhibit No. 59.

Vinod, H. D. (1976b, December), Application of ridge regression to a study of Bell System scale economies. Journal of the American Statistical Association, 71, 835-841.

\section{Copyrights}

Copyright for this article is retained by the author(s), with first publication rights granted to the journal.

This is an open-access article distributed under the terms and conditions of the Creative Commons Attribution license (http://creativecommons.org/licenses/by/4.0/). 